\title{
Simulation-based cost-utility analysis of population screening-based alendronate use in Switzerland
}

\author{
M. Schwenkglenks $\cdot$ K. Lippuner
}

Received: 15 November 2006 / Accepted: 25 April 2007 / Published online: 26 May 2007

(C) International Osteoporosis Foundation and National Osteoporosis Foundation 2007

\begin{abstract}
Summary A simulation model adopting a health system perspective showed population-based screening with DXA, followed by alendronate treatment of persons with osteoporosis, or with anamnestic fracture and osteopenia, to be cost-effective in Swiss postmenopausal women from age 70 , but not in men.

Introduction We assessed the cost-effectiveness of a population-based screen-and-treat strategy for osteoporosis (DXA followed by alendronate treatment if osteoporotic, or osteopenic in the presence of fracture), compared to no intervention, from the perspective of the Swiss health care system. Methods A published Markov model assessed by first-order Monte Carlo simulation was refined to reflect the diagnostic process and treatment effects. Women and men entered the model at age 50. Main screening ages were 65,75 , and 85 years. Age at bone densitometry was flexible for persons fracturing before the main screening age. Realistic assumptions were made with respect to persistence with intended 5 years of alendronate treatment. The main outcome was cost per quality-adjusted life year (QALY) gained.

Results In women, costs per QALY were Swiss francs (CHF) 71,000, CHF 35,000, and CHF 28,000 for the main screening ages of 65,75 , and 85 years. The threshold of CHF 50,000 per QALY was reached between main
\end{abstract}

\footnotetext{
M. Schwenkglenks $(\bowtie)$

European Center of Pharmaceutical Medicine,

University of Basel,

ECPM Research, c/o ECPM Executive Office,

University Hospital,

4031 Basel, Switzerland

e-mail: m.schwenkglenks@unibas.ch

K. Lippuner

Osteoporosis Policlinic, University Hospital Bern,

Bern, Switzerland
}

screening ages 65 and 75 years. Population-based screening was not cost-effective in men.

Conclusion Population-based DXA screening, followed by alendronate treatment in the presence of osteoporosis, or of fracture and osteopenia, is a cost-effective option in Swiss postmenopausal women after age 70 .

Keywords Alendronate $\cdot$ Bone densitometry $\cdot$ Cost-utility analysis $\cdot$ Modelling studies $\cdot$ Osteoporosis $\cdot$ Switzerland

\section{Introduction}

Osteoporosis is a chronic, systemic disease, characterised by low bone mass and deterioration of bone microarchitecture, leading to increased fracture risk [1]. Osteoporotic fragility fractures may occur at any skeletal site [2]. However, fractures of the hip, the spine and the distal forearm are the most frequent osteoporotic fracture types [3], representing $82 \%$ and $75 \%$ of all incident osteoporotic fractures in Swiss women and men, respectively [4]. The lifetime risk of any osteoporotic fracture approximates $50 \%$ in women and $20 \%$ in men [5]. Fractures result in significant morbidity $[6,7]$, mortality $[8,9]$, and reductions in quality of life [10].

Osteoporosis has a profound and growing impact on health care resource utilization, especially in industrialized countries. The direct expenditures for the treatment of osteoporotic fractures were estimated at US dollar (USD) 10-15 billion per year for the USA [11], a figure which is consistent with Swiss francs (CHF) 713 million reported for Switzerland for the year 2000 [4]. These costs are expected to substantially increase in the coming decade, due to the overall ageing of the population and to the exponential increase of fracture incidence with age $[4,12]$. 
Drug therapy of osteoporosis is generally indicated in patients who have had a prior fragility fracture and in patients who have osteoporosis according to the WHO densitometric definition (i.e., T-score $\leq-2.5$ SD) [1]. Alendronate, an aminobisphosphonate, has been previously shown, in randomised controlled primary endpoint fracture trials [13-15] and in meta-analyses of such trials [16, 17], to reduce fracture risk at all clinically relevant sites, including the hip, in postmenopausal women with osteoporosis defined as low BMD with or without prevalent vertebral fractures. In addition, the efficacy and safety of long-term treatment of osteoporosis with alendronate was established for up to 10 years of continuous therapy [18]. Furthermore, the efficacy profile of alendronate for reducing fracture risk was established in men with primary osteoporosis $[19,20]$ and in the most frequent form of secondary osteoporosis, glucocorticosteroid-induced osteoporosis, in women and in men [21].

Several studies have suggested that the treatment of osteoporosis with alendronate is cost-effective [22-30] with an incremental cost-utility ratio (ICUR) of less than USD 50,000 per quality adjusted life year (QALY) gained. However, these studies generally did not consider the cost involved with the identification of cases of osteoporosis which deserve therapeutic intervention, with only two exceptions, one study in glucocorticosteroid-induced osteoporosis [30] and one recent publication by Schousboe et al. [27]. In the latter work, the health benefits and costs of universal screening of elderly women, followed by alendronate treatment of those identified with osteoporosis (screen-and-treat strategy) were assessed from the societal perspective. The cost per QALY gained was estimated at USD 43,000 and USD 5,600 for 65 and 75-year-old women, respectively, while the intervention was found to be cost-saving for older women [27]. However, this model observed the screened populations from the age of mass screening onwards only and did not take into account the effect of cases identified and treated earlier (e.g., due to fractures occurring before the main screening age).

In Switzerland, as in many other European countries, bone densitometry with DXA is not accepted for mass screening of osteoporosis and reimbursement is limited to indications resulting from case-finding strategies. Drug treatment is reimbursed for persons with a T-score $\leq$ $-2.5 \mathrm{SD}$ or in the presence of one or more fragility fractures. Whether and for which subset of the population mass screening with DXA, followed by drug treatment where indicated, would be cost-effective remains unknown.

Using an adapted version of our published model [12], the present study aimed at assessing the cost-effectiveness of mass bone densitometry screening plus subsequent alendronate therapy, compared to no drug treatment of osteopenia and osteoporosis, in the Swiss population from age 50 onwards, from the perspective of the Swiss health care system. We took into account the impact of earlier fracture events, which have already led to "pre-screening age" diagnostic activities. We hypothesized that even if the diagnostic process is taken into account in the modelling, the cost-effectiveness of subsequent drug intervention will still be preserved in specific patient groups.

\section{Materials and methods}

The cost-effectiveness of two alternative strategies was evaluated in a simulation-based incremental cost-utility analysis from the perspective of the Swiss health care system. For this purpose, a non-intervention strategy was compared to a screen-and-treat strategy defined as i) bone densitometry screening with DXA at a predefined main screening age or if a fracture occurred after age 50, and ii) alendronate $\left(\right.$ FOSAMAX $^{\circledR}$; Merck \& Co) treatment in subjects with osteoporosis (T-score $\leq-2.5 \mathrm{SD}$ ), or with confirmed osteopenia (T-score $>-2.5$ SD but $<-1.0 \mathrm{SD}$ ) after a fracture event [31]. The time horizon for analysis was life-long from age 50 on in the main analysis. Direct medical costs were taken into account regardless of payer.

For women and men, the outcomes of the screen-andtreat strategy were assessed for main screening ages of 65 , 75 , and 85 years, and for three treatment options each: treatment with alendronate for 5 years [25] with full persistence (to assess the theoretical potential); treatment with alendronate for 5 years with realistic persistence; and treatment with alendronate for 10 years with realistic persistence.

Additional specifications were: re-screening once after 3 years if osteopenic at first measurement (in the absence of fracture); assessment of all persons presenting with a fracture and treatment if osteopenic or osteoporotic; treatment initiation without additional screening if a fracture occurred and an earlier screening had already confirmed the presence of osteopenia; no repeated initiation of alendronate treatment in the same person; no initiation of treatment after age 95 .

The main outcome was the incremental cost per QALY gained (incremental cost-utility ratio; ICUR) of each screen-and-treat scenario vs. the no intervention scenario.

In the absence of an accepted cost-effectiveness threshold for Switzerland, ICUR results of less than CHF 50,000 per QALY gained were regarded as cost-effective. Taking different price structures into account [32], one can regard this choice as roughly equivalent to the thresholds of USD 50,000 per QALY, and of British pound (GBP) 20,000 30,000 per QALY, which have been used for the USA and the United Kingdom, respectively [33, 34]. CHF 1 equalled USD 0.80 on June 30, 2006. 


\section{Model characteristics}

Key model characteristics were previously described [12]. Briefly, a Markov state transition model with four mutually exclusive health states (alive without fracture; alive with at least one distal forearm or vertebral fracture, but no hip fracture; alive with at least one hip fracture; dead) was developed to simulate the number of osteoporotic hip, vertebral, and distal forearm fractures as a function of demographic change and other influences. This model was analysed using individual, first-order Monte Carlo simulation, and was pre-designed to be adaptable for assessing the impact of different screening, prophylactic, and treatment strategies on fracture occurrence and associated cost, allowing for a wide variety of scenarios regarding planned medication usage, drug efficacy, and individual persistence with treatment. Cycle length was one month. For the purpose of this study, the model was adapted as follows:

1. The increase in relative fracture risk observed in persons with a history of previous fracture; in those suffering from osteopenia or osteoporosis; and in nursing home residents was additionally modelled. The technical implementation was such that the average gender- and age-specific fracture incidences remained unaffected.

2. The probability of having osteopenia or osteoporosis at model entry, or of developing any of these conditions, was modelled using gender- and age-specific prevalence estimates and transition probabilities derived from these.

3. The impact of alendronate usage was modelled using published relative risks (RRs).

4. Age at model entry was kept constant while screening age was considered variable in the different scenarios, in order to accommodate for the fact that at a given main screening age, some persons may already have been identified with and treated for osteoporosis.

5. In order to take into account the difference between fracture-associated mortality and mortality causally related to fracture, the estimates of life years gained through alendronate usage were corrected downwards in a separate step, outside the main model. The "life expectancy component" of the QALY results was corrected in the same way.

\section{Model inputs}

Published or publicly available Swiss data sources were used whenever available. Otherwise, European data were preferred to US data, and were adjusted for regional differences within Europe. Gender- and age-specific population-level fracture risks and other models inputs used in the previously published model version were retained with the exception of osteoporosis attribution probabilities, which were no longer used to model osteoporotic causation of fracture events [12]. Additional inputs comprised the following.

Prevalence of osteopenia/osteoporosis was assumed to be similar as seen in the NHANES III study for a caucasian US population, based on femoral neck BMD measurements $[35,36]$. In the absence of published Swiss BMD data, a local DXA reference database from the Bern Canton supported this assumption. Technical implementation used the results of the Rotterdam Study, with data points available for both genders and all relevant age groups [37]. Compared with NHANES III, the Rotterdam data showed a higher prevalence, consistent with the north-south gradient of osteoporosis prevalence in Europe. Therefore, a downwards adjustment was performed, using the following correction factors: 0.80 for osteopenia and osteoporosis in women; 0.65 for osteoporosis and 0.75 for osteopenia in men. This resulted in average prevalences of $23 \%$ and $8 \%$ (osteoporosis), and of $49 \%$ and $46 \%$ (osteopenia), in women and men from age 50 , respectively. These figures are consistent with the NHANES III results $[35,36]$. The incidence of osteopenia and osteoporosis was estimated using transition probabilities derived from these prevalence data.

Prevalence of any previous fracture was derived from a recent meta-analysis exploring the relationship of any previous fracture with age, sex and bone mineral density in 15,259 men and 44,902 women from 11 cohorts followed for a total of 250,000 person-years [38].

Relative fracture risks In the presence of osteoporosis or osteopenia, RRs of 2.7 or 1.3, respectively, as reported in the Rotterdam Study, were used for non-vertebral fractures in women and men [37]. Identical RRs were assumed for vertebral fractures [39]. BMD-adjusted RRs of 1.7 for women and of 2.0 for men were used to take into account the presence of previous fracture [38]. For nursing home residents, a RR for hip fracture of 3.5 was assumed, based on the only recent Swiss publication available [40]. This figure is consistent with previously published Swiss [41] and US data [42, 43]. No increased risk of vertebral and distal forearm fracture was assumed for this group [44, 45]. The above RRs compare persons who have the risk factor of interest with persons who do not have it. In combination with absolute fracture risk (gender- and age-specific, but averaged across other risk factors), and gender- and agespecific patterns of risk factor prevalence, they provided a basis for deriving individualised fracture risks as they were finally used in the modelling.

The $R R$ of fracture during alendronate treatment in women with osteoporosis was generally assumed to be 0.5 , in accordance with published primary endpoint trials and 
meta-analyses [13-17, 28]. However, a more conservative RR of 0.6 was assumed for non-vertebral fractures after age 85 [29, 46]. In women with osteopenia, the RR was conservatively assumed to be 0.7 for vertebral fractures [15] and 1.0 for other fractures. Identical assumptions were used for men [20]. The effect of alendronate has been shown to be present early in treatment [47]. For the purpose of this analysis, it was assumed to be present from day 1 of therapy, given that the above RR estimates represent averages across the entire observation periods of the underlying studies. After the end of alendronate administration, we assumed a linear decline of the alendronate effect to zero over a 5 -year period $[18,48]$, or over a period equal to the given person's treatment duration, whichever was shorter.

Persistence with alendronate treatment was assumed to decline linearly from $100 \%$ to $65 \%$ during year 1 and from $65 \%$ to $45 \%$ between end of year 1 and the end of the intended duration of use [49]. It was assumed that those who stopped drug treatment prematurely did no longer accrue drug costs.

Mortality Twenty-five percent of the deaths associated with hip fracture were considered to be causally related in the base case scenario [50]. Consequently, the life years gained through alendronate usage, as reported by the model, were multiplied with a correction factor of 0.25 . No such adjustment was made for vertebral fracture-associated excess deaths whose number was considered to be too low to meaningfully impact on the overall results, especially when compared to the remaining uncertainty about hip fracture-related excess mortality [48, 51]. To account for an increased general morbidity of persons admitted to nursing homes, in the absence of published data, a correction factor of 0.9 was applied to the crude hip fracture-related extra time spent in nursing homes, for the base case analysis.

Utilities associated with health states As no Swiss data were available, population-based European (Danish) data were used as shown in Table $1[23,52]$. These baseline

Table 1 European (Danish) population utility values ${ }^{1}$

\begin{tabular}{ll}
\hline Age & Average utility \\
\hline 50 & 0.917 \\
55 & 0.9199 \\
60 & 0.8992 \\
65 & 0.8882 \\
70 & 0.8939 \\
75 & 0.863 \\
80 & 0.8529 \\
85 & 0.8339 \\
\hline
\end{tabular}

${ }^{1}$ Pedersen et al. 2003 [23, 52]. utilities were adjusted downwards after fracture occurrence, by applying multiplication factors as reported by Kanis et al. (Table 2) [53]. It was assumed that 2 nd year factors would also apply for subsequent years. In addition, 1st year and subsequent years factors for the combination of a hip and a clinical vertebral fracture were assumed to be 0.489 and $0.714[27,54]$. Utility and multiplication factor measurements involved the time trade off method and the EQ-5D [52-54].

Costs Unit cost estimates were real cost estimates for the year 2000. The monthly cost of alendronate treatment was set at CHF 61.36, based on the public price of marketed alendronate in Switzerland in 2005 adjusted for the health system-specific price inflation between 2000 and 2005 of $3.4 \%$, as published by the Swiss Federal Office of Statistics (SFOS). Based on expert opinion and Swiss tariff lists, the cost of each screening episode was estimated at CHF 300, covering bone densitometry and a medical consultation with typical services performed. Daily inpatient costs were CHF 1,009 for acute care hospitals, CHF 440 for inpatient rehabilitation facilities, and CHF 187 for nursing homes, as reported by the SFOS for the year 2000. Overall inpatient costs were modelled individually as previously described [12]. To give some reference points, average acute care length of stay was 17.4 days for hip fracture, 18.0 days for vertebral fracture and 6.4 days for distal forearm fracture. The probability of being hospitalised was assumed to be $33 \%$ after a vertebral fracture coming to clinical attention [3, 55] and 53\% after a distal forearm fracture [12]. Participation in an inpatient rehabilitation program after hip fracture was assumed to occur in $68 \%$ of women and $36 \%$ of men, with a length of stay of 59 and 54 days, respectively [56]. Ambulatory treatment costs post fracture was estimated at CHF 6,442 for a hip fracture, based on published data [57]. They were estimated at CHF 2,250 for a vertebral fracture and at CHF 1,750 for a distal forearm fracture, irrespective of whether an initial hospitalisation

Table 2 Utility correction factors

\begin{tabular}{|c|c|c|c|c|}
\hline Fracture site & $\begin{array}{l}\text { Female, } \\
1 \text { st year }\end{array}$ & $\begin{array}{l}\text { Male, } \\
1 \text { st } \\
\text { year }\end{array}$ & $\begin{array}{l}\text { Female, } \\
\text { subsequent } \\
\text { years }\end{array}$ & $\begin{array}{l}\text { Male, } \\
\text { subsequent } \\
\text { years }\end{array}$ \\
\hline Wrist $^{1}$ & 0.977 & 0.977 & 0.999 & 0.999 \\
\hline Vertebrae $^{1}$ & 0.820 & 0.777 & 0.913 & 0.912 \\
\hline Hip $^{1}$ & 0.792 & 0.792 & 0.813 & 0.813 \\
\hline $\begin{array}{l}\text { Hip and clinical } \\
\text { vertebral } \\
\text { fracture }^{2}\end{array}$ & 0.489 & 0.489 & 0.714 & 0.714 \\
\hline
\end{tabular}


occurred. These estimates were based on expert opinion as there were no published Swiss data available.

Discount rate The discount rate for costs and QALYs was set at $3 \%$.

\section{Sensitivity analysis}

In the base case scenarios, model entry was at age 50 for all persons, which allowed to take into account the impact of cases of osteoporosis or osteopenia with intercurrent fracture, identified before the main screening age. In alternative scenarios, intended for comparison purposes, the simulated persons entered the model at the main screening age, i.e., their previous diagnosis and treatment history was neglected.

Additional, univariate sensitivity analyses were conducted to identify influential input parameters. Specifically, average population fracture risks; the risk reduction achieved with alendronate; the utility reduction due to fracture events; and most cost parameters were varied by $\pm 30 \%$. The cost of outpatient fracture treatment was varied by $\pm 50 \%$, due to the higher level of uncertainty present in the underlying estimates. The linear offset post alendronate administration was set to 0.4 or 1.6 times the treatment duration, corresponding to a 2 -year or 8 -year linear offset for a treatment duration of 5 years. Persistence with alendronate treatment was assumed to decline from $100 \%$ to either $40 \%$ or $80 \%$ during year 1 , and to decline further to either $20 \%$ or $60 \%$ between end of year 1 and the end of the intended duration of use [49]. The correction for non-causally related hip fracture-associated deaths was set to $15 \%$ or $50 \%$, and the correction of hip fracture-related nursing home time for increased general co-morbidity of nursing home residents was set to 0.6 or 1.0 , the latter representing no correction. The probability of a new nursing home admission after hip fracture was set to $10 \%$ or $25 \%$ [12]. The discount rate was set to $0 \%$ or $6 \%$.

Subsequently, probabilistic sensitivity analyses were run on the main scenarios. Triangular distributions, based on the base case values and the above described ranges of variation, were used to vary the above-listed parameters jointly. As an exception, a uniform distribution was used to vary the correction of hip fracture-related nursing home time for increased general co-morbidity of nursing home residents, in the absence of published values. The discount rate was not varied in probabilistic sensitivity analysis.

Technical implementation

The model was implemented using TreeAge Pro 2006 Suite ${ }^{\circledR}$ (TreeAge, Williamstown, USA). TreeAge's option to independently seed each model iteration allowed to greatly reduce the amount of random variation present in the simulation results. Additional statistical analyses were performed in $\mathrm{Stata} / \mathrm{SE}^{\circledR}$, version 9 (Stata Corporation, College Station, USA). Main scenarios and univariate sensitivity analyses were based on 100,000 simulated persons per arm, for each scenario. Probabilistic sensitivity analyses used 500 different sets of input parameters (randomly drawn from the above-mentioned triangular distributions) and 2,000 simulated persons per set of input parameters and arm [27].

Model validation

All validations performed on the previously published model [12] retained their validity. Expected gender- and age-specific prevalences of osteoporosis and osteopenia were reproduced correctly. After model calibration, the overall fracture incidence rates found for a cohort followed for the rest of their lives from age 50 onwards, without alendronate treatment, deviated only slightly from the incidence rates calculated from the previously published model (deviations in women: hip fracture $0.7 \%$; vertebral fracture $0.2 \%$; distal forearm fracture $0.2 \%$, deviations in men: hip fracture $-0.3 \%$; vertebral fracture $0.0 \%$; distal forearm fracture $-3.3 \%$ ). A simulation of 50,000 virtual persons receiving alendronate, under the assumption of perfect persistence and a relative risk of fracture of 0.5 , correctly reduced fracture incidences by $50 \%$. Two scenarios mimicking the previously published models of Christensen et al. [23] and Johnell et al. [25] delivered similar results in terms of expected relative fracture risk reduction. Calculation of $95 \%$ confidence intervals based on bias-corrected bootstrapping using 1,000 repetitions confirmed standard errors for the main outcomes of interest to be sufficiently small compared to effect sizes. (Data not shown).

\section{Results}

Results for the primary outcome measure, incremental cost per QALY gained (ICUR), are shown in Table 3, for both genders. Table 3 covers the base case scenarios (where all persons entered the model at age 50) as well as the alternative scenarios (where all persons entered the model at the main screening age; to enhance comparability with results published earlier by Schousboe et al. [27]). The incremental costs of, and QALYs gained with a screen-andtreat strategy compared to no intervention, assuming model entry at age 50 and 5 years of intended treatment with alendronate if applicable, under realistic persistence assumptions, are shown for women and men in Table 4. 
Table 3 Incremental cost-utility ratio in CHF per quality-adjusted life year gained, for women and men, by main screening age

\begin{tabular}{|c|c|c|c|}
\hline $\begin{array}{l}\text { Main } \\
\text { screening } \\
\text { age }\end{array}$ & $\begin{array}{l}5 \text { years } \\
\text { alendronate, } \\
\text { persistence } \\
100 \%\end{array}$ & $\begin{array}{l}5 \text { years } \\
\text { alendronate, } \\
\text { realistic } \\
\text { persistence }\end{array}$ & $\begin{array}{l}10 \text { years } \\
\text { alendronate, } \\
\text { realistic } \\
\text { persistence }\end{array}$ \\
\hline \multicolumn{4}{|l|}{ Women } \\
\hline & \multicolumn{3}{|c|}{ Age at model entry, 50 years } \\
\hline 65 years & 55,729 & 70,995 & 61,280 \\
\hline 75 years & 24,170 & $35,412^{1}$ & 30,155 \\
\hline \multirow[t]{2}{*}{85 years } & 19,433 & 28,170 & 34,341 \\
\hline & \multicolumn{3}{|c|}{ Age at model entry equals main screening age } \\
\hline 65 years & 45,545 & 55,533 & 46,805 \\
\hline 75 years & 5,045 & 11,904 & 7,245 \\
\hline 85 years & Cost-saving & Cost-saving & Cost-saving \\
\hline \multicolumn{4}{|l|}{ Men } \\
\hline & \multicolumn{3}{|c|}{ Age at model entry, 50 years } \\
\hline 65 years & 149,682 & 197,460 & 162,509 \\
\hline 75 years & 95,559 & 123,094 & 113,178 \\
\hline \multirow[t]{2}{*}{85 years } & 93,184 & 118,945 & 123,973 \\
\hline & \multicolumn{3}{|c|}{ Age at model entry equals main screening age } \\
\hline 65 years & 135,638 & 176,670 & 147,991 \\
\hline 75 years & 60,269 & 85,911 & 73,526 \\
\hline 85 years & 30,763 & 48,268 & 50,413 \\
\hline
\end{tabular}

${ }^{1} \mathrm{CHF} 21,502$ per quality-adjusted life year gained if assuming no diagnostic or treatment activity before the age of mass screening.

ICUR results were better when model entry was at the main screening age (i.e., when the possibility of earlier diagnosis and treatment was disregarded); better in women than in men; better if perfect persistence was assumed; and better if the intended treatment duration was extended from 5 to 10 years under realistic persistence assumptions. However, the latter was not observed when the main screening age was set to 85 years.

In women, the ICUR of the screen-and-treat strategy compared to no intervention was less than CHF 50,000 for a main screening age of 75 years or higher, in the base case scenario. In the alternative scenarios, ICUR results were below or around CHF 50,000 for all main screening ages considered. Although the alternative scenarios showed overall improved cost-effectiveness results, the relative rank order of the assessed strategies remained identical. An additional analysis under realistic persistence assumptions showed that, in women, a screen-and-treat strategy using a main screening age of 70 years lead to ICURs of CHF 49,101 and CHF 42,141 for 5 and 10 years of intended alendronate treatment, respectively. However, the screen-and-treat approach did not appear to be cost-effective for a main screening age of 65 years or below, or in men.

The impact of univariate sensitivity analysis on the ICUR is shown in Table 5, for a representative scenario (women; model entry at age 50; main screening age
Table 4 Incremental cost of and quality-adjusted life years (QALYs) gained with a screen-and-treat strategy compared to no intervention, per 1,000 persons

\begin{tabular}{lll}
\hline & Women & Men \\
\hline Main screening age 65 years & & \\
QALYs gained (years) & 8.34 & 2.05 \\
Incremental cost (CHF) & 591,920 & 405,190 \\
Main screening age 75 years & & \\
QALYs gained (years) & 9.85 & 2.04 \\
Incremental cost (CHF) & 348,750 & 251,570 \\
Main screening age 85 years & & \\
QALYs gained (years) & 5.44 & 1.01 \\
Incremental cost (CHF) & 153,340 & 120,210 \\
\hline
\end{tabular}

Specifications: model entry at age 50; intended duration of alendronate treatment 5 years; realistic persistence

75 years; intended duration of alendronate treatment 5 years; realistic persistence). For this scenario, parameter changes favouring the comparator strategy yielded moderate increases of the ICUR, which remained below or very close to CHF 50,000 in all instances. Variation of the risk reduction achieved with alendronate, of the duration of the residual alendronate effect after the end of drug administration, and of the cost of drug treatment had the strongest impact. The parameters which exerted the smallest influence were the correction for increased general morbidity of persons admitted to nursing homes, the probability of a new nursing home admission after hip fracture, and the cost of outpatient fracture treatment.

For this same scenario, probabilistic sensitivity analysis indicated that the cost-effectiveness criterion of CHF 50,000 per QALY gained was met in $79 \%$ of cases, with a $95 \%$ confidence interval for the ICUR reaching from costsaving to CHF 79,525 per QALY gained (Fig. 1). Under identical assumptions, but with the main screening age set to 65 years, the CHF 50,000 per QALY threshold was only reached in $16 \%$ of the cases.

\section{Discussion}

The present study demonstrates that, from the perspective of the Swiss health care system, mass bone densitometry screening at or after age 70 , plus subsequent alendronate therapy for 5 or 10 years (screen-and-treat strategy for osteoporosis and osteopenia), is a cost-effective intervention in women, with an ICUR around or below CHF 50,000 per QALY gained. This finding is based on realistic assumptions with respect to persistence with drug treatment and takes into account the impact of diagnostic and treatment activities before the age of mass screening, induced by "pre-screening age" fracture occurrence. It is 
Table 5 Univariate sensitivity analysis of incremental cost-utility ratio for women

\begin{tabular}{|c|c|c|c|c|}
\hline Parameter varied & Range of variation & $\begin{array}{l}\text { Favours } \\
\text { screening/ } \\
\text { alendronate use }\end{array}$ & Baseline & $\begin{array}{l}\text { Favours } \\
\text { comparator } \\
\text { strategy }\end{array}$ \\
\hline $\begin{array}{l}\text { Fracture risk (average population } \\
\text { risk) }\end{array}$ & $+30 \% /-30 \%$ & 22,775 & 35,412 & 45,512 \\
\hline Fracture risk, effect of alendronate & Relative reduction of risk, $+30 \% /-30 \%$ & 18,062 & 35,412 & 52,543 \\
\hline $\begin{array}{l}\text { Duration of effect of alendronate after } \\
\text { end of administration }\end{array}$ & Linear offset, 1.6/0.4 times duration of administration & 25,409 & 35,412 & 50,131 \\
\hline Persistence (persons taking drug) & $\begin{array}{l}\text { Decline to } 40 \% / 80 \% \text { in year } 1 \text {, further decline to } 20 \% / \\
60 \% \text { between end of year } 1 \text { and end of intended } \\
\text { duration of use }\end{array}$ & 30,149 & 35,412 & 46,374 \\
\hline $\begin{array}{l}\text { Causally related hip fracture- } \\
\text { associated deaths }\end{array}$ & $50 \% / 15 \%$ & 25,525 & 35,412 & 41,904 \\
\hline $\begin{array}{l}\text { Correction for increased general } \\
\text { morbidity in persons admitted to } \\
\text { nursing homes }\end{array}$ & $1.0 / 0.6$ & 34,751 & 35,412 & 37,395 \\
\hline $\begin{array}{l}\text { Probability of new nursing home } \\
\text { admission after hip fracture }\end{array}$ & $10 \% / 25 \%$ & 31,334 & 35,412 & 37,989 \\
\hline Disutility factors & Relative utility reduction, $+30 \% /-30 \%$ & 29,272 & 35,412 & 44,812 \\
\hline Cost of alendronate & $-30 \% /+30 \%$ & 22,002 & 35,412 & 48,822 \\
\hline $\begin{array}{l}\text { Cost of diagnostic work-up before } \\
\text { initiation of alendronate therapy }\end{array}$ & $-30 \% /+30 \%$ & 29,988 & 35,412 & 40,836 \\
\hline $\begin{array}{l}\text { Cost of inpatient treatment inclusive } \\
\text { of nursing home stays }\end{array}$ & $+30 \% /-30 \%$ & 28,325 & 35,412 & 42,499 \\
\hline Cost of outpatient fracture treatment & $-50 \% /+50 \%$ & 34,289 & 35,412 & 36,535 \\
\hline Discount rate & $0 \% / 6 \%$ & 20,904 & 35,412 & 47,807 \\
\hline
\end{tabular}

Specifications: model entry at age 50, main screening age 75 years; intended duration of alendronate treatment 5 years; realistic persistence

hence in line with the stated hypothesis. In contrast, a screen-and-treat strategy for osteoporosis and osteopenia does not appear to be cost-effective in men.

Increasing the intended duration of alendronate treatment from 5 to 10 years leads to improved ICUR results in most cases. However, for a main screening age of 85 years, this was no longer true. At this age, all-cause mortality rates are very high and cost savings due to avoided fracture events may no longer be able to outweigh the additional cost of further treatment.

Our results demonstrate further that in situations where fixed upfront costs (not influenced by persistence; such as screening costs) have a substantial role, sub-optimal persistence can have a relevant negative impact on ICUR results.

Our screen-and-treat strategy assumed, in contrast to current clinical practice in Switzerland and other countries [58], that all persons fracturing before the main screening age would immediately be assessed, and treated with alendronate if osteopenic or osteoporotic. Not allowing for such "pre-screening age" diagnostic and treatment activities leads to improved cost-effectiveness results because on average, alendronate is now administered at a higher age and when fracture incidences are also higher, at the cost of not protecting an easily identifiable risk group at an earlier age.
To our knowledge, the only other modelling study assessing a mass screen-and-treat strategy for osteoporosis was recently published by Schousboe et al. [27]. These authors compared the combination of DXA screening plus alendronate treatment from a US perspective. Their approach was conceptionally close to ours, with some remarkable differences. The present model used Swiss or European data whenever available; all scenarios were assessed for women and for men; the strategies modelled took into account osteopenia in addition to osteoporosis; and realistic assumptions were made with respect to persistence with alendronate treatment in the base case analysis. Most importantly, we observed the target population from age 50 onwards (and not from the age of mass screening onwards, which scotomizes any diagnostics performed earlier, and treatments administered earlier, due to fracture occurrence before the main screening age). This scotomization and a related difficulty to individually model "pre-screening age" fracture-induced changes in healthrelated quality of life and utility may have lead to an overestimation of the cost-effectiveness of the screen-andtreat approach, in particular when a very high main screening age was chosen. In order to clarify this point, we performed alternative assessments with model entry at 

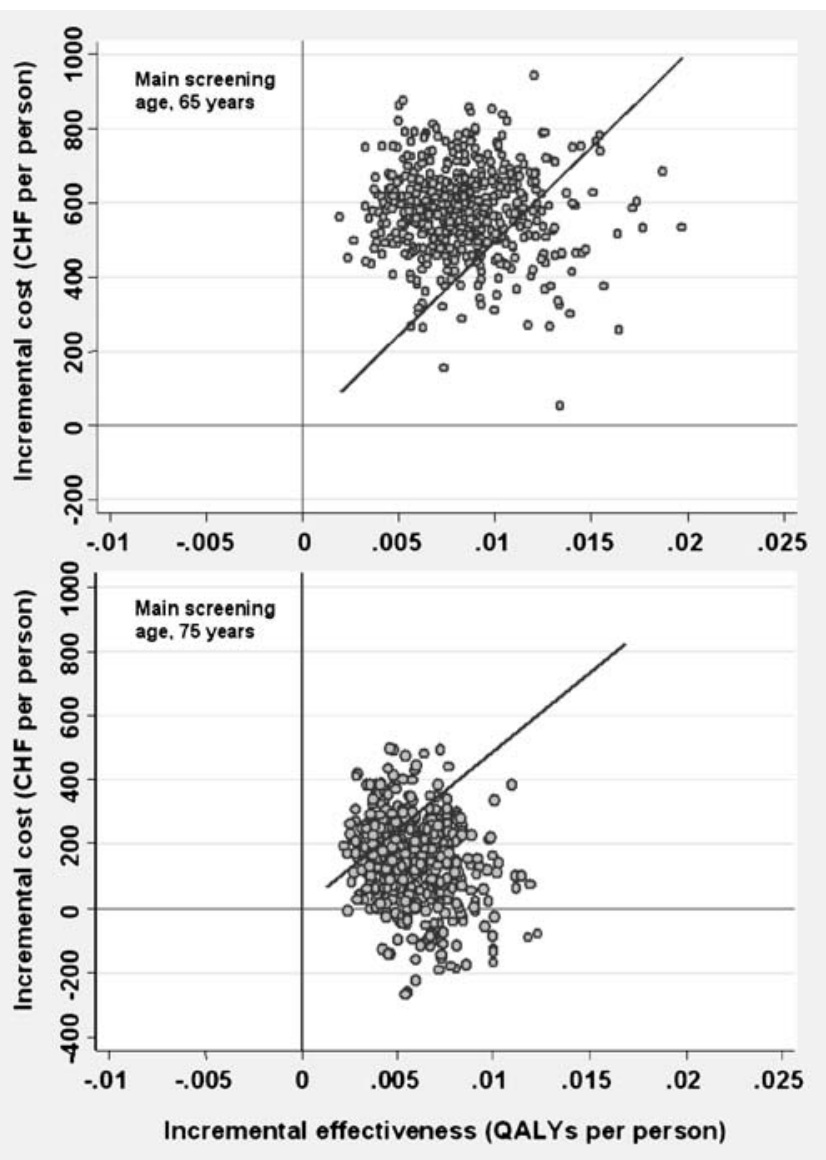

Fig. 1 Probabilistic sensitivity analysis of incremental cost-utility ratio of DXA-based screening and subsequent alendronate treatment, compared to no intervention, for women. Specifications: model entry at age 50; intended duration of alendronate treatment 5 years; realistic persistence; main screening ages 65 years (top) and 75 years (bottom). Slant lines represent the cost-effectiveness threshold of CHF 50,000 per quality-adjusted life year gained

the main screening age. The resulting set of more favourable ICUR values was entirely consistent with the results reported by Schousboe et al. [27]. In both cases, the gain in costeffectiveness achieved by choosing a higher main screening age was distinctly bigger than in our analyses observing the target population from age 50 onwards. Observing the target population from the age of mass screening onwards only, or otherwise disregarding diagnostic and treatment activities before the main screening age, tends to overestimate cost-effectiveness in general, and the advantages of choosing a high screening age in particular.

This study has some limitations. The proposed results and conclusions are model-based, which always implies a simplification of reality. This remains true although we adapted our published model [12] to incorporate the screening and diagnostic process (in contrast to other modelling studies addressing the cost-effectiveness of alendronate $[23,25])$; to take into account increases in relative fracture risk in persons with anamnestic fractures or with low BMD; and to correct for the discrepancy between fracture-associated deaths and deaths causally related to fracture $[23,25]$. The co-morbidity patterns of osteoporotic fracture patients are likely to differ from those of the general population and we implemented a correction for increased general morbidity in persons who were admitted to a nursing home post hip fracture. However, little detailed knowledge is available on this topic, which may have a significant impact on patient outcomes and on the costeffectiveness of intervention which could not be adequately reflected in our model and deserves further research.

The model did not encompass all types of osteoporotic fractures but was limited to three typical fracture sites. About $18-25 \%$ of osteoporotic fractures were shown to occur at other skeletal sites not considered in the present analysis [4]. This may have led to a certain underestimation of the cost-effectiveness of the screen-and-treat approach.

We made realistic assumptions with respect to persistence with drug treatment, but in order to limit complexity, it was assumed that no further drug costs were accrued by those persons who stopped taking the drug prematurely. Moreover, given that alendronate is currently taken as a weekly tablet, the possibility of additional compliance effects (such as reduced effectiveness due to omission of individual doses or taking the drug in the wrong way) was neglected. This may have caused a certain overestimation of the costeffectiveness of the screen-and-treat approach.

Only some of our model inputs could be based on published or official Swiss data [12]. Other model inputs had to be derived from various European or US sources, had to be based on expert opinion, or were subject to relevant uncertainty otherwise (e.g., persistence with drug treatment; residual treatment effect after the end of drug administration). However, univariate and probabilistic sensitivity analyses confirmed the robustness of the ICUR results. Based on variation within a $\pm 30 \%$ range, the risk reduction achieved with drug treatment was the most sensitive single parameter.

The applicability of our results is in essence limited to Switzerland, as Swiss cost and resource use data were used. Some transferability to other industrialised countries with similar cost and age structures can be assumed, but cannot be taken for granted. Transferability to other treatments of osteoporosis may neither be without problems. Separate calculations would be required, based on a thorough assessment of reported effect sizes, related levels of empirical evidence, and other related input parameters (e.g., expected persistence).

Finally, this study did not assess the cost-effectiveness of scenarios involving a pre-selection of sub-populations at high risk of osteoporosis. Earlier studies have shown that selective case-finding based on a combination of risk factors, with or without radiographic absorptiometry, 
provided a better sensitivity and specificity in identifying women with underlying osteoporosis than the currently accepted criteria for reimbursement of DXA measurements in Switzerland [59]. In addition, the pre-selection of women and men at highest risk of osteoporosis, and who should therefore undergo BMD measurement by DXA, based on the determination of their 10-year absolute fracture risk may considerably improve the cost-effectiveness of the population-based screen-and-treat approach [60-64]. More research work is required in this field.

In Switzerland, as in other European countries, universal screening for osteoporosis with bone densitometry using DXA is not recommended and patient identification solely relies on case-finding strategies based on anamnestic fractures and/or other risk factors for osteoporosis. For the USA, medical interventions have been considered as costeffective from a societal point of view if their cost was below USD 50,000-100,000 per QALY gained [33]. Allowing for different price structures in the USA vs. Switzerland, the cost-effectiveness threshold adopted here, of CHF 50,000 per QALY, is at the lower end of this range, and was used in an assessment only taking into account direct medical costs. It corresponds to 0.9 times the Swiss gross domestic product (GDP) per capita in the year 2000 (while use of a factor of 1.4-2.1 times the GDP per capita has been tentatively estimated for the UK [65]), and must, thus, be considered as conservative. With this restrictive assumption, this is the first European study to demonstrate that population-based screening with bone densitometry by DXA and subsequent alendronate treatment in the presence of osteoporosis, or of anamnestic fracture and osteopenia, is cost-effective in women from age 70 onwards and should, therefore, be regarded as a valid option from a Swiss health care system point of view.

Generic alendronates may become available in Switzerland in the future. By Swiss law, no cost-effectiveness assessment of new generics is required if they are marketed at least $30 \%$ below the price of the original drug [66]. Based on their lower price, such generic alendronates may contribute to further improve the cost-effectiveness of the screen-and-treat option. Our corresponding univariate sensitivity analysis result of CHF 22,002 per QALY gained reflects this theoretical potential, if it is assumed that the clinical efficacy, tolerability and safety of the original compound will be matched.

Although the incremental cost-utility ratio remains superior if a high main screening age is chosen, the difference seen is distinctly smaller than reported earlier [27], leaving more room for the notion that it may be more important from an individual, but also from a societal perspective to avoid fracture events at a younger rather than at a later age, despite higher absolute budget implications due to differences in the size of the populations to be screened. If and for which population segments the costeffectiveness of the screen-and-treat approach can be further improved, e.g., by pre-selection of eligible candidates for screening based on clinical risk factor profiles, should be subject to further research.

Acknowledgements We are grateful to Dr Philippe Kress for his invaluable contribution to the manuscript.

Funding This study was partially funded by an unrestricted research grant from Merck Sharp \& Dohme-Chibret AG, Glattbrugg, Switzerland.

\section{References}

1. (1993) Consensus development conference: diagnosis, prophylaxis, and treatment of osteoporosis. Am J Med 94:646-650

2. Seeley DG, Browner WS, Nevitt MC et al (1991) Which fractures are associated with low appendicular bone mass in elderly women? The study of osteoporotic fractures research group. Ann Intern Med 115:837-842

3. Cummings SR, Melton LJ (2002) Epidemiology and outcomes of osteoporotic fractures. Lancet 359:1761-1767

4. Lippuner K, Golder M, Greiner R (2005) Epidemiology and direct medical costs of osteoporotic fractures in men and women in Switzerland. Osteoporos Int 16(Suppl 2):S8-S17

5. Johnell O, Kanis J (2005) Epidemiology of osteoporotic fractures. Osteoporos Int 16(Suppl 2):S3-S7

6. Pasco JA, Sanders KM, Hoekstra FM et al (2005) The human cost of fracture. Osteoporos Int 16:2046-2052

7. Melton LJ 3rd (2003) Adverse outcomes of osteoporotic fractures in the general population. J Bone Miner Res 18:1139-1141

8. Nydegger V, Rizzoli R, Rapin CH et al (1991) Epidemiology of fractures of the proximal femur in Geneva: incidence, clinical and social aspects. Osteoporos Int 2:42-47

9. Johnell O, Kanis JA, Oden A et al (2004) Mortality after osteoporotic fractures. Osteoporos Int 15:38-42

10. Lips P, van Schoor NM (2005) Quality of life in patients with osteoporosis. Osteoporos Int 16:447-455

11. (2001) NIH consensus development panel on osteoporosis prevention, diagnosis, and therapy. JAMA 285:785-795

12. Schwenkglenks M, Lippuner K, Hauselmann HJ et al (2005) A model of osteoporosis impact in Switzerland 2000-2020. Osteoporos Int 16:659-671

13. Black DM, Cummings SR, Karpf DB et al (1996) Randomised trial of effect of alendronate on risk of fracture in women with existing vertebral fractures. Fracture intervention trial research group. Lancet 348:1535-1541

14. Black DM, Thompson DE, Bauer DC et al (2000) Fracture risk reduction with alendronate in women with osteoporosis: the fracture intervention trial. FIT research group. J Clin Endocrinol Metab 85:4118-4124

15. Cummings SR, Black DM, Thompson DE et al (1998) Effect of alendronate on risk of fracture in women with low bone density but without vertebral fractures: results from the Fracture Intervention Trial. JAMA 280:2077-2082

16. Papapoulos SE, Quandt SA, Liberman UA et al (2005) Metaanalysis of the efficacy of alendronate for the prevention of hip fractures in postmenopausal women. Osteoporos Int 16:468-474 
17. Cranney A, Wells G, Willan A et al (2002) Meta-analyses of therapies for postmenopausal osteoporosis. II. Meta-analysis of alendronate for the treatment of postmenopausal women. Endocr Rev 23:508-516

18. Bone HG, Hosking D, Devogelaer JP et al (2004) Ten years' experience with alendronate for osteoporosis in postmenopausal women. N Engl J Med 350:1189-1199

19. Ringe JD, Faber H, Dorst A (2001) Alendronate treatment of established primary osteoporosis in men: results of a 2-year prospective study. J Clin Endocrinol Metab 86:5252-5255

20. Orwoll E, Ettinger M, Weiss S et al (2000) Alendronate for the treatment of osteoporosis in men. N Engl J Med 343:604-610

21. Saag KG, Emkey R, Schnitzer TJ et al (1998) Alendronate for the prevention and treatment of glucocorticoid-induced osteoporosis. Glucocorticoid-Induced Osteoporosis Intervention Study Group. N Engl J Med 339:292-299

22. Borgstrom F, Johnell O, Jonsson B et al (2004) Cost effectiveness of alendronate for the treatment of male osteoporosis in Sweden. Bone 34:1064-1071

23. Christensen PM, Brixen K, Gyrd-Hansen D et al (2005) Costeffectiveness of alendronate in the prevention of osteoporotic fractures in Danish women. Basic Clin Pharmacol Toxicol 96:387-396

24. Goeree R, Blackhouse G, Adachi J (2006) Cost-effectiveness of alternative treatments for women with osteoporosis in Canada. Curr Med Res Opin 22:1425-1436

25. Johnell O, Jonsson B, Jonsson L et al (2003) Cost effectiveness of alendronate (fosamax) for the treatment of osteoporosis and prevention of fractures. Pharmacoeconomics 21:305-314

26. Liu H, Michaud K, Nayak S et al (2006) The cost-effectiveness of therapy with teriparatide and alendronate in women with severe osteoporosis. Arch Intern Med 166:1209-1217

27. Schousboe JT, Ensrud KE, Nyman JA et al (2005) Universal bone densitometry screening combined with alendronate therapy for those diagnosed with osteoporosis is highly cost-effective for elderly women. J Am Geriatr Soc 53:1697-1704

28. Stevenson M, Lloyd Jones M, De Nigris E et al (2005) A systematic review and economic evaluation of alendronate, etidronate, risedronate, raloxifene and teriparatide for the prevention and treatment of postmenopausal osteoporosis. Health Technol Assess 9(22)

29. Schousboe JT, Nyman JA, Kane RL et al (2005) Cost-effectiveness of alendronate therapy for osteopenic postmenopausal women. Ann Intern Med 142:734-741

30. Solomon DH, Kuntz KM (2000) Should postmenopausal women with rheumatoid arthritis who are starting corticosteroid treatment be screened for osteoporosis? A cost-effectiveness analysis. Arthritis Rheum 43:1967-1975

31. Kanis JA (2002) Diagnosis of osteoporosis and assessment of fracture risk. Lancet 359:1929-1936

32. Organisation for Economic Co-operation and Development (OECD) (2007) Purchasing Power Parities (PPP). http://www. oecd.org/department/0,2688,en_2649_34357_1_1_1_1_1,00.html

33. Ubel PA, Hirth RA, Chernew ME et al (2003) What is the price of life and why doesn't it increase at the rate of inflation? Arch Intern Med 163:1637-1641

34. Devlin N, Parkin D (2004) Does NICE have a cost-effectiveness threshold and what other factors influence its decisions? A binary choice analysis. Health Econ 13:437-452

35. Looker AC, Johnston CC Jr, Wahner HW et al (1995) Prevalence of low femoral bone density in older U.S. women from NHANES III. J Bone Miner Res 10:796-802

36. Looker AC, Orwoll ES, Johnston CC Jr et al (1997) Prevalence of low femoral bone density in older U.S. adults from NHANES III. J Bone Miner Res 12:1761-1768

37. Schuit SC, van der Klift M, Weel AE et al (2004) Fracture incidence and association with bone mineral density in elderly men and women: the Rotterdam Study. Bone 34:195-202
38. Kanis JA, Johnell O, De Laet C et al (2004) A meta-analysis of previous fracture and subsequent fracture risk. Bone 35:375-382

39. Marshall D, Johnell O, Wedel H (1996) Meta-analysis of how well measures of bone mineral density predict occurrence of osteoporotic fractures. BMJ 312:1254-1259

40. Chevalley T, Herman FR, Delmi M et al (2002) Evaluation of the age-adjusted incidence of hip fractures between urban and rural areas: the difference is not related to the prevalence of institutions for the elderly. Osteoporos Int 13:113-118

41. Schürch MA, Rizzoli R, Mermillod B et al (1996) A prospective study on socioeconomic aspects of fracture of the proximal femur. J Bone Miner Res 11:1935-1942

42. Chandler JM, Zimmerman SI, Girman CJ et al (2000) Low bone mineral density and risk of fracture in white female nursing home residents [see comments]. JAMA 284:972-977

43. Sugarman JR, Connell FA, Hansen A et al (2002) Hip fracture incidence in nursing home residents and community-dwelling older people, Washington State, 1993-1995. J Am Geriatr Soc 50:1638-1643

44. Cooper C, Atkinson EJ, O'Fallon WM et al (1992) Incidence of clinically diagnosed vertebral fractures: a population-based study in Rochester, Minnesota, 1985-1989. J Bone Miner Res 7:221-227

45. Graafmans WC, Ooms ME, Bezemer PD et al (1996) Different risk profiles for hip fractures and distal forearm fractures: a prospective study. Osteoporos Int 6:427-431

46. McClung MR, Geusens P, Miller PD et al (2001) Effect of risedronate on the risk of hip fracture in elderly women. Hip intervention program study group. N Engl J Med 344:333-340

47. Levis S, Quandt SA, Thompson D et al (2002) Alendronate reduces the risk of multiple symptomatic fractures: results from the fracture intervention trial. J Am Geriatr Soc 50:409-415

48. Tosteson AN, Jonsson B, Grima DT et al (2001) Challenges for model-based economic evaluations of postmenopausal osteoporosis interventions. Osteoporos Int 12:849-857

49. Clowes JA, Peel NF, Eastell R (2004) The impact of monitoring on adherence and persistence with antiresorptive treatment for postmenopausal osteoporosis: a randomized controlled trial. J Clin Endocrinol Metab 89:1117-1123

50. Kanis JA, Oden A, Johnell O et al (2003) The components of excess mortality after hip fracture. Bone 32:468-473

51. Melton LJ 3rd (2000) Excess mortality following vertebral fracture. J Am Geriatr Soc 48:338-339

52. Pedersen K, Wittrup-Jensen K, Brooks R et al (2003) Værdisætning af sundhed-teorien om kvalitetsjusterede leveår og en dansk anvendelse. Syddansk Universitetsforlag, Odense

53. Kanis JA, Johnell O, Oden A et al (2004) The risk and burden of vertebral fractures in Sweden. Osteoporos Int 15:20-26

54. Tosteson AN (2001) Impact of hip and vertebral fractures on quality adjusted life years. Osteoporos Int 12:1042-1049

55. Bonjour JP, Burckhardt P, Dambacher M et al (1997) Epidemiology of osteoporosis. Schweiz Med Wochenschr 127:659-667

56. Trombetti A, Herrmann F, Hoffmeyer P et al (2002) Survival and potential years of life lost after hip fracture in men and agematched women. Osteoporos Int 13:731-737

57. Szucs TD, Häuselmann HJ (2000) Die Wirtschaftlichkeit von Alendronat in der Behandlung der postmenopausalen Osteoporose. Gesundh Ökon Qual Manag 5:99-106

58. Hooven F, Gehlbach SH, Pekow P et al (2005) Follow-up treatment for osteoporosis after fracture. Osteoporos Int 16:296-301

59. Gasser KM, Mueller C, Zwahlen M et al (2005) Osteoporosis case finding in the general practice: phalangeal radiographic absorptiometry with and without risk factors for osteoporosis to select postmenopausal women eligible for lumbar spine and hip densitometry. Osteoporos Int 16:1353-1362

60. Abrahamsen B, Vestergaard P, Rud B et al (2006) Ten-year absolute risk of osteoporotic fractures according to BMD T score 
at menopause: the Danish osteoporosis prevention study. J Bone Miner Res 21:796-800

61. Johnell O, Kanis JA, Oden A et al (2005) Predictive value of BMD for hip and other fractures. J Bone Miner Res 20:1185-1194

62. Kanis JA, Johnell O, Oden A et al (2005) Ten-year probabilities of clinical vertebral fractures according to phalangeal quantitative ultrasonography. Osteoporos Int 16:1065-1070

63. Kanis JA, Johnell O, Oden A et al (2001) Ten year probabilities of osteoporotic fractures according to BMD and diagnostic thresholds. Osteoporos Int 12:989-995
64. Kanis JA, Johnell O, Oden A et al (2002) Ten-year risk of osteoporotic fracture and the effect of risk factors on screening strategies. Bone 30:251-258

65. Eichler HG, Kong SX, Gerth WC et al (2004) Use of costeffectiveness analysis in health-care resource allocation decisionmaking: how are cost-effectiveness thresholds expected to emerge? Value Health 7:518-528

66. Swiss Federal Office of Public Health (2007) Änderungen im Handbuch betreffend die Spezialitätenliste (SL) 2007. Swiss Federal Office of Public Health, Bern 